\title{
The Emergence of Sex Differences
}

\section{Citation}

Kagan, Jerome. 1972. The Emergence of Sex Differences. The School Review 80(2): 217-227.

\section{Published Version}

doi:10.1086/443027

\section{Permanent link}

http://nrs.harvard.edu/urn-3:HUL.InstRepos:25277896

\section{Terms of Use}

This article was downloaded from Harvard University's DASH repository, and is made available under the terms and conditions applicable to Other Posted Material, as set forth at http:// nrs.harvard.edu/urn-3:HUL.InstRepos:dash.current.terms-of-use\#LAA

\section{Share Your Story}

The Harvard community has made this article openly available.

Please share how this access benefits you. Submit a story.

\section{Accessibility}




\section{The Emergence of Sex Differences}

J E R O M E K A A N

Harvard University

The current preoccupation with psychological sex differences has generated a debate concerning the degree to which these differences are purely the result of history or the partial consequence of biological differences between the sexes. A useful strategy is to assume that the earlier a particular behavioral difference appears in the life cycle, the more likely it is influenced by biological factors. If a 7-day-old boy is more active than a 7-day-old girl, we are tempted to conclude that this variety derives from biological factors - either heredity or pre- or perinatal conditions. This paper summarizes what we have learned about sex differences in the opening two years of life.

Before beginning the discussion, it is important to note that biological differences do not place serious constraints on the kinds of vocational and social roles men and women should assume in our society. Even if a small proportion of occupations-and it is probably less than 1 percent-is biologically better suited to one sex, most roles in Western society can probably be filled with competence by men or women. Thus the reader should regard the present essay as an intellectual adventure, not a sociopolitical treatise.

Although most of the research on sex differences has been

Copyright (C) 1971 by McGraw-Hill, Inc. This article is from the chapter "Psychology of Sex Differences" by Jerome Kagan to be published in the forthcoming book on Human Sexuality edited by Frank Beach. Used with permission of McGraw-Hill Book Company. 
atheoretical, it is helpful to organize the knowledge we have gained along theoretical dimensions. We shall try to synthesize this discussion around the following four dimensions: susceptibility to fear, cognitive functioning, variability, and social class.

\section{Susceptibility to Fear}

Most investigations of male and female infants during the first eighteen months of life report that there is a slight tendency for the infant female to display fear and anxiety more frequently and more intensely than the male. For example, in a typical experimental situation a mother and her 1-year-old infant are brought into a strange room in a university laboratory. Under these conditions the girl is more likely to remain near her mother or in physical contact with her for a much longer period of time than the boy. If the room contains toys, the boy is likely to venture out after fifteen or twenty seconds; the girl, perhaps, only after a minute. Moreover, in more restricted laboratory situations, where unusual visual or auditory stimuli are presented to a child, the female infant under l year is more likely to cry and show distress than is the male. In one of our experiments we found that twice as many 4-month-old girls as boys cried in the service of fear in a strange laboratory. ${ }^{1}$

There seems to be some generality to this finding, for the same sex difference occurs among rhesus monkeys. Mitchell found that female rhesus infants are likely to stay closer to their mothers than male infants during the first two months of life. ${ }^{2}$ Since the mother pushes her son away from her but restrains her daughter, this difference is not due solely to the fact that the male infants have a disposition to wander.

The reason for this sex difference in susceptibility to fear is not clear. One possibility is that the male is more likely to issue

JEROME KAGAN is professor of human development at Harvard University. His major research interest is cognitive and personality development during the first decade of life with emphasis on the predictive consequences of individual differences during the infant period. 
a response in an uncertain situation. The activation of a response tends to buffer fear. That is, beginning at around 4 months of age, girls begin to inhibit active motoric responses in a strange situation, while boys remain active. If a mother and infant are placed behind a wire barrier and the mother puts her infant on one side, 1-year-old girls are more likely to freeze, while boys are more likely to initiate some action. The boy might see a piece of paper on the floor and examine it, or try to shake the barrier. Each of these responses diverts the child from the source of frustration or uncertainty and aborts the fear. We believe that action has the capability of forestalling fear when a child is in an uncertain situation. Thus, if boys have a natural disposition to action in situations that are uncertain, even though a particular behavior may have no relevance for the uncertainty, the boy may be protected from emerging fear. In any case, the girl infants' earlier display of fear, motor inhibition, and tendency to stay close to the primary caretaker are not easily interpreted as a result of differential treatment by parents and, therefore, are likely to be a partial product of biology.

A second explanation for the earlier display of fear, in addition to the suggestion that boys are more likely to act in an uncertain situation, is the fact that the infant female is biologically ahead of the male. Growth of the myelin sheath around the axons of the central nervous system and the development of bone and muscle are precocious in the female. If this known precocity in biological functions is paralleled by precocious psychological functioning, a set of important corolaries follows.

The first elements of knowledge the infant develops are called schemata. A schema should be viewed as an abstract representation of an experience. Before the second month has passed all infants have developed schemata for some of the events in the world around them. If a female were precocious, she might develop these schemata sooner and possess, at an earlier age, a better articulated idea of her life space. An event that is slightly different from the original one that produced the schema-called a discrepant event-alerts the infant and 
motivates him to understand the unfamiliar - that is, to resolve the uncertainty the discrepant event generated. A 4-month-old baby who has a representation for his crib and room at home becomes alerted if he is placed in a strange bed. The infant can cope with this discrepant event by assimilating it or withdrawing from it. If either of these reactions occurs, the infant will not cry. However, if the infant can neither assimilate nor withdraw, he becomes afraid. The earlier and more frequent occurrences of fear, in the girl, in discrepant situations may reflect the fact that she has developed better articulated schemata than the boy. She is alerted by new situations but cannot understand them; hence, she cries more often. This hypothesis is supported by the fact that first-born girls who were most fearful in a laboratory setting when they were 4 months old displayed the most creative play with toys when they were 13 months old. This continuity between early fear and creative play nine months later did not occur for boys. ${ }^{3}$

In most young mammals withdrawal is the preferred response to fear. If the infant habitually withdraws as a response to fear during the first year of life, a strong tendency to display that behavior can be established. If this argument has any merit, it might help explain why girls and older women are more likely to withdraw and show more cautiousness in fearful contexts than males.

However, we must acknowledge the possibility that the more frequent female withdrawal could result from tendencies favoring retreat under conditions of uncertainty. If male and female rhesus monkeys are raised in isolated chambers from birth and brought together as adults, the females tend to withdraw, while males are likely to attack. ${ }^{4}$ These different actions cannot be the result of differential growth of schemata, since both animals had the same environment and both were subadults when tested. At the moment, we do not have enough information to allow us to choose between these two hypotheses to explain the behavioral facts. Moreover, it is possible that both arguments have some merit, and that the female not only has a stronger tendency to withdraw but is also precocious in cognitive development. 


\section{Cognitive Functioning}

There is a second implication that stems from the fact that females are precocious compared with males. The paired cerebral hemispheres of the brain become increasingly asymmetric with respect to relative dominance of one over the other as the child grows. It has been suggested that, in the newborn infant, the cerebral hemispheres are of approximately equal dominance; but, with age, the left hemisphere gradually gains dominance over the right. ${ }^{5}$ For most individuals the major site of language function is in the left hemisphere, although a capacity for language comprehension is contained in the right hemisphere. If the girl were developmentally precocious, she would attain left-hemisphere dominance at a faster rate than the boy, perhaps because of precocious myelination of the corpus callosum and the medial surface of the temporal lobe. If this were true, then the important speech functions contained in the left hemisphere would develop at a faster rate among girls than boys. This deduction fits well with the fact that preschool girls generally begin to speak a few months earlier than boys, and their speech is more comprehensive, more accurate, and more complex. But since the boy eventually develops a language as complex and rich as the girl's, it is possible that the girl only has a temporary advantage.

Support for the idea that language functions do develop earlier in girls is found in an extensive longitudinal study of first-born white children from 4 to 27 months of age. ${ }^{6}$ During the first year of life nonmeaningful vocalizations, often called babbling, are a better index of the state of excitability to interesting events among girls than boys. If a tape recorder plays a sample of human speech to 8-month-olds, the girls who are most attentive to that speech are most likely to vocalize for a few seconds after the speech ends. No such relation exists for boys. Further, the educational level of the girl's family is an excellent predictor of the degree to which she increases her vocalizations during the last half of the first year. The boy's social class is unrelated to changes in vocalization over that same period. 
In general, young girls who vocalized frequently during the last half of the first year were, at 3 years of age, more active and more excitable than quiet female infants. No comparable relation occurred among the boys. These data, as well as others, indicate that babbling in the infant girl is a sensitive index of the excitement generated by interesting experience. This inference is in accord with the fact that babbling scores on infant intelligence tests in the first year are better predictors of future intellectual functioning among preschool girls than among boys. ${ }^{7}$ The likelihood that differences in brain functioning are related to language competence is supported by an interesting study performed on adult epileptic patients who had an epileptic focus in either the right or left temporal lobe. Some adult patients had part of the left temporal lobe surgically removed, while others had part of the right temporal lobe removed. Following surgery, both language and nonlanguage tests were administered to all patients. For those who lost the left temporal lobe, verbal functioning was more seriously impaired in women than in men. Removal of the right hemisphere, which seems to be important for competence on nonverbal tasks, impaired performance on spatial reasoning more seriously for men than for women. ${ }^{8}$ This finding tentatively supports the possibility of sex differences in brain functioning. These data seem reliable enough to invite additional inquiry. Although they do not come close to proving that there are sex differences in central nervous system organization, they are sufficiently strong to suggest that this possibility should be entertained. Indeed, the special link between vocalization and attentional excitement in the infant girl may be a joint product of central nervous system organization and special caretaking practices toward daughters. Since societies are likely to adopt practices that are friendly to the biological attributes of the organism, both hypotheses may have merit.

We might note that Western culture has produced many creative women poets and writers. However, in the nonverbal art forms-music and painting-there are far fewer women than one would expect, considering their numbers in the language arts. Perhaps this asymmetry in choice of creative mode 
is the price women pay for their initial left hemispheric advantage. Perhaps it is woman, not man, who is the intellectual specialist; woman, not man, who insists on interlacing sensory experience with meaning. These reversals of popular homilies join other maxims that science has begun to question. For now we know that it is the female, not the male, who is most predictable; the female, not the male, who is biologically more resistant to infirmity; the female's anatomy, not the male's, that is nature's preferred form. Man's a priori guesses about sex differences have reflected an understandable but excessive masculine narcissism.

\section{Sex Differences in Variability}

In addition to sex differences in precocity, the female also shows less variability for many biological attributes. More boys than girls are extreme on dimensions like height, weight, and bone growth. There are more very tall and very short men, more very heavy and very light men. This variability in physical growth also holds for tested intelligence. We have known for many years that there are more men than women who have very high or very low IQ scores.

The greater male variability is accompanied by weaker long-term continuity for both psychological and physical variables. As indicated above, height, weight, or number of ossification centers in the wrist are more predictable from one age to another among females than among males. Analogously, IQ scores and grades in school are more predictable over time for girls than for boys.

If biological factors led to more extreme instances of lethargy or irritability among boys than girls, one would expect a different relation between familial experience and future development. This possibility forms a liaison with our last theme.

Sex Differences in Relation to Social Class

Many studies of Western children have found a closer correlation for girls than boys between indexes of cognitive development and social class. Moreover, this pattern occurs not only in the United States but also in Europe and rural areas of 
Guatemala. Typically the correlation between social class (as measured by education and occupation in the United States or by type of housing and sanitation in rural, primitive areas) and some index of cognitive development, be it attentiveness during infancy or IQ score during school age, is higher for girls than for boys. ${ }^{9}$ The question is, How do we interpret this replicable and provocative phenomenon?

The differences in correlation between social class of family and cognitive achievement among girls of school age is understandable if we assume that the girl is more likely to adopt the values of her family than the boy. This is a reasonable assumption. Since there is a major difference in concern with intellectual development between poor and affluent parents, we should get larger covariation between social class and indexes of cognitive achievement for girls than for boys. However, this mechanism could not operate during the first year of life, when the child does not have a motive to adopt the values or skills of his parent. At this early age, it is likely that there is greater variability across social-class levels in a mother's reaction to her daughter than to her son. Most mothers in the United States, regardless of their social class, tend to believe their sons should develop independence, a sense of responsibility, and some vocational role. When working-class and middle-class mothers of preschool children were asked to teach their child a new task, mothers of both classes were more achievement oriented toward their sons than toward their daughters and adopted a much more businesslike posture toward their sons. ${ }^{10}$

Poor mothers seemed to project their greater sense of impotence and inadequacy onto their daughters more than onto their sons and were less likely to encourage or give high praise to their daughter's simple accomplishments. Middle-class mothers spend more time talking to and entertaining their daughters and also chide them more often for task incompetence. ${ }^{11}$ In one of our longitudinal studies, we visited a large group of children when they were 27 months of age. The observer recorded descriptive statements that dealt with aspects of the mother-child interaction. There were no class 
differences for most of the dimensions that we studied. However, when a class difference in maternal behavior emerged, it was more likely to be for daughters than for sons. The most striking difference occurred for punishment of incompetent behavior. Upper-middle-class mothers were much more likely to note incompetent behavior and criticize it in their daughters than in their sons.

We noted all the incidents that provoked the mother to criticize or punish her child. Less than 1 percent involved incompetence among lower-middle-class boys, upper-middleclass boys, or lower-middle-class girls. However, 2.4 percent of the maternal criticisms of the child involved this particular violation for the middle- and upper-middle-class mothers. Well-educated mothers of daughters were three times more likely than poorly educated ones to chide the daughter for not performing up to a standard held by the mother. ${ }^{12}$ This difference was specific to task competence, for the welleducated mothers were more tolerant of other kinds of violations in their daughters than were the working-class mothers. Other studies with older children reveal that first-born girls experience a greater pressure for competent performance on problems. Mothers of preschool daughters are more likely to remind them of incompetent performance and be intrusive while the child is working at the problems. We are suggesting that the mothers from a broad range of social and educational backgrounds differ more in their preoccupation with intellectual development in their daughters than in their sons, and this phenomenon could explain the greater correlation between maternal social class and cognitive development among girls.

In addition, the sex differences in variability alluded to earlier imply that there are more infant boys than girls who are extremely irritable, alert, or lethargic. If, as a result of biological factors, an infant is at the extreme of a psychological dimension, he should be less influenced by specific caretaking practices than a child of more normative temperament. For it is difficult to play for long periods of time reciprocally with a highly mobile, highly apathetic, or highly irritable infant. Thus 
the mother who initiates these caretaking actions with an infant of extreme temperament will influence the child less than one who initiates the same sequence with a less extreme child. This would lead to a poorer correlation between a mother's practices and the child's subsequent development for boys than for girls.

There is some reason to believe that social experience does affect girls' development in a more orderly fashion than that of boys. Three-month-old infants were observed in their home with their mothers, and the amount of face-to-face contact between mother and child was noted. After these observations were made in the home, the infants came to the laboratory and looked at representations of human faces, as well as geometric stimuli. The girls who experienced the most face-to-face interaction in the home were most attentive toward the faces, but this relationship did not hold for boys. Moreover, the tendency to remain quiet at 1 month and show low irritability at 3 months was a good predictor of high attentiveness among the boys but not among girls. ${ }^{13}$ One interpretation is that specific experiences with the mother exert a major influence on the subsequent attentiveness of the girl, while congenital temperament is more influential for boys. The effect of experience in the home is more faithfully reflected in the infant girl than in the infant boy. Perhaps greater male variability in both maturational development and display of temperamental attributes is responsible for this difference.

We have summarized some of the early differences that emerge in the young infant before the first two years of life are over, and have suggested that some may be biological in origin and lead to slightly different developmental routes for boys and girls. However, these differences are subtle, not blatant, and the environment has power to modify them. Since environments accommodate to the temperamental and biological attributes of children, it is likely that there always has been and will continue to be an intimate interaction between experience and biology that tempts men and women in any society to march to slightly different pipers and to be gratified by events that the other sex disregards. 
Preparation of this paper was supported in part by research grant HD4299 from NICHD, United States Public Health Service, and a grant from the Carnegie Corporation of New York.

1. Jerome Kagan, Change and Continuity in Infancy (New York: John Wiley \& Sons, 1971).

$\rightarrow$ G. D. Mitchell, "Attachment Differences in Male and Female Infant Monkeys," Child Development 39 (1968): 611-20.

3. Kagan.

4. G. D. Mitchell, "Persistent Behavior Pathology in Rhesus Monkeys Following Early Social Isolation," Folia Primatologica 8 (1968): 132-47.

5. M. S. Gazzaniga, The Bisected Brain (New York: Appleton-CenturyCrofts, Inc., 1970).

6. Kagan.

7. T. Moore, "Language and Intelligence - a Longitudinal Study of the First Eight Years," Human Development 10 (1967): 88- 106.

8. H. Lansdell, "The Use of Factor Scores from the Wechsler-Bellevue Scale of Intelligence in Assessing Patients with Temporal Lobe Removal," Cortex 4 (1968): 257-68.

9. E. E. Werner, "Sex Differences in Correlations between Children's IQs and Measures of Parental Ability and Environmental Ratings," Developmental Psychology 1 (1969): 280-85.

10. R. D. Hess et al., "The Cognitive Environments of Urban Preschool Children" (report to the Graduate School of Education, University of Chicago, 1968 and 1969).

$1 \rightarrow$ M. K. Rothbart, "Birth Order and Mother Child Interaction in an Achievement Situation," Journal of Personality and Social Psychology 17 (1971): 113- 20.

12. C. M. Minton, J. Kagan, and J. A. Levine, "Mother-Child Interaction in 27-Month-Old Children," Child Development (1971), in press.

$1 \rightarrow$ H. A. Moss and K. S. Robson, "The Relation between Amount of Time Infants Spend in Various States and the Development of Visual Behavior," Child Development 41 (1970): 509- 17. 